УДК $620.92(597)$

ББК 65.049

МОДЕЛЬ ФОРМИРОВАНИЯ РЕГИОНАЛЬНОГО КЛАСТЕРА ВОЗОБНОВЛЯЕМЫХ ИСТОЧНИКОВ ЭНЕРГИИ ВО ВЬЕТНАМЕ

\author{
НГО АНЬ ТУЕТ \\ tuyetna@epu.edu.vn \\ аспирант кафедры «Экономика и организация энергетики» \\ Белорусский национальный технический университет \\ Минск, Республика Беларусь
}

В статье описаны основные шаги предлагаемой модели формирования регионального кластера возобновляемых источников энергии Вьетнама. Данная модель предлагается к использованию с учетом авторской методики оченки возможности создания регионального кластера вознобляемых источников энергии. Проведена апробаџия модели на основе региона Нинь Туан - Бинь Туан.

Ключевые слова: модель, возобновляемые источники энергии, кластеризация, регион, возможности кластеризации.

\title{
MODEL OF FORMING REGIONAL CLUSTER OF RENEWABLE ENERGY SOURCES IN VIETNAM
}

\author{
NGO ANH TUYET \\ postgraduate student \\ of the Chair «Economics and Organization of Power Engineering» \\ Belarusian National Technical University \\ Minsk, Republic of Belarus
}

The article presents the main steps of model of forming regional cluster of renewable energy sources in Vietnam, including method of evaluating the possibility of creating regional cluster of renewable energy resources in Vietnam. The approbation of model in region Ninh Thuan - Binh Thuan.

Keywords: model, renewable energy sources, clusterization, region, possibility of clusterization.

\section{ВВЕДЕНИЕ}

В последние годы понятие «кластер» все более широко используется и признаётся в качестве неотъемлемой части стратегий развития регионов. В теории под кластером понимается концентрированные по географическому признаку группы взаимосвязанных компаний, специализированных поставщиков, поставщиков услуг, фирм в родственных отраслях, а также связанных с их деятельностью организаций, в определенных областях, конкурирующих, но при этом ведущих совместную работу [1]. С точки зрения географии, кластером может быть город, регион, страна или даже группа соседних государств. Применение кластерного метода наиболее актуально именно на региональном уровне вследствие необходимости тесного контакта между участниками кластера, что предполагает некоторое территориальное ограничение. Только расположение в одном регионе позволяет быстро встретиться, обсудить общую задачу, оперативно решить проблему, а также 
определить то направление деятельности, которое является для данной территории наиболее конкурентоспособным сейчас и будет выгодным в будущем.

\section{РЕЗУЛЬТАТЫ И ИХ ОБСУЖДЕНИЕ}

Возобновляемые источники энергии (ВИЭ) - это новая область энергетики, вызывающая интерес во многих странах мира. Однако, эта отрасль пока слабо развита. Для развития ВИЭ согласно с общей целю развития страны необходима поддержка. Формирование кластера ВИЭ становиться приоритетом для многих стран мира. Формирование кластеров ВИЭ осуществляется в соответствии с социально-экономическими условиями и энергетическими потенциалами каждой страны.

Основной задачей кластера ВИЭ является производство продукта и услуг в области использования ВИЭ для производства электроэнергии и тепла, энергосбережения, эффективного использования энергии, снижения выбросов $\mathrm{CO}_{2}$ и защиты окружающей среды. Основная цель кластера ВИЭ сосредоточивается на технологии и (или) услугах в области ВИЭ. Основными объектами, рассматриваемыми в кластере ВИЭ, являются участники энергетического рынка: малые и средние компании, которые представляют сектор солнечной энергетики, сектор биомассы или другие секторы ВИЭ. Средние и малые компании имеют преимущество в виде коммерческой гибкости, но в то же время они имеют ограниченные ресурсы и отсутствие опыта, отсутствие рынков сбыта, отсутствие программ поддержки. При объединении этих компаний последние будут иметь возможность большего влияния на усиление конкуренции в получении доли рынка как в торговле, так и в производстве [2].

Во Вьетнаме Правительство начало рассматривать развития возобновляемых источников энергии в качестве замены ископаемого источника и устойчивого развития. Для того, применяются различные методы поддержки развития ВИЭ. В их числефинансовая поддержка, налоговые и тарифные льготы, административная поддержка. Однако все перечисленные методы поддержки разрозненные, нецентрализованные или предназначаются только одному определенному типу технологии, не соединяя при этом различные технологии, не связывая продавцов и покупателей на рынке. В этих условиях формирование кластера возобновляемых источников энергии является новой и необходимой политикой для Вьетнама. Кластеризация возобновляемых источников энергии может содействовать решению проблемы стимулирования технологических инноваций, внедряемых в целях повышения возможности применения различных технологий возобновляемых источников, а также поддерживать участников электроэнергетического рынка. Таким образом, благодаря созданию энергетического кластера, конкурентоспособность возобновляемых источников энергии (по сравнению с традиционными источниками энергии) в рамках энергетической системы страны значительно повыситься [3].

Специфика и особенности процесса кластеризации достаточно широко представлены в научных трудах: М. Портера [1], Б. С. Дондоковой [4], Н. А. Анисовой [5], Н. Н. Котлярова [6].

Наиболее подходящими методиками кластеризации региона являются подходы таких авторов, как Е. В. Маркушиной [7], И. Н. Свистунова [8], Чэнь Цзаньчжана [9], А. В. Глоовой [10], В. И. Волкова [11].

Энергетические кластеры представлены в трудах А. Р. Садриева [12], А. А. Батталовой [13], П. В. Игумнова [14].

Специфика и особенности процесса кластеризации ВИЭ рассмотрены в научных трудах Ю. Г. Лавриковой [15], В. И. Велькина [16], В. Р. Киушкиной [0]. 
Но на наш взгляд, наиболее подходящими методиками кластеризации региона и в сфере энергетики являются подходы авторов А. А. Батталовой, В. Р. Киушкиной, Г. А. Денисова и В. И. Велькина $[13 ; 16 ; 18 ; 17]$.

Денисов Г. А. предложил алгоритм реализации инновационного организационнопроектного развития регионального кластера, который предусматривает реализацию комплекса действий по: выполнению подготовительных организационно-правовых мероприятий; проведению кластеризации; определению целей, задач и функций администрации кластера в целом и его составляющих, а также установление взаимосвязи кластера как целостного интегрированного образования с отдельными хозяйствующими субъектами. Реализация этих действий позволяет сформировать кластеры региональной экономической системы, произвести их классификацию и определить основные направления их стратегического развития [18].

Автором В. И. Велькиным предложена математическую модель, учитывающую ряд значимых факторов для поиска оптимального кластера ВИЭ. Использование многофакторной модели позволяет определить оптимальную конфигурацию кластера ВИЭ по составу и установленной мощности оборудования. Расчетная модель эффективности кластера позволяет оптимизировать кластер ВИЭ по составу оборудования и критерию минимальной стоимости выработки 1 кВт-ч [16].

Автором А. А. Батталовой был разработан экономический механизм устойчивого развития топливно-энергетического комплекса на основе его кластеризации. В этом случае, кластеризация состоит из следующих этапов:

1. Разработка механизма формирования топливно-энергетического кластера.

2. Разработка схемы оценки потенциала кластеризации отрасли:

- оценка социально-экономических параметров развития региона;

- расчет коэффициентов локализации;

- Расчет коэффициентов интеграции для оценки эффективности кластера.

3. Разработка схемы отбора включения предприятий в кластер.

4. Создание модели топливно-энергетического кластера [13].

В свою очередь В. Р. Киушкина предложила методику исследования потенциала ВИЭ на основе проведения кластерного анализа ресурсов возобновляемой энергетики. Данная комплексная оценка потенциала ВИЭ связана с изучением расположения в пространстве потенциала ВИЭ, выявлением перспективных районов для внедрения автономных систем электроснабжения на базе возобновляемых источников. Кластеризация потенциала ВИЭ была произведена с географической привязкой к административно-территориальному делению для получения предварительных рекомендаций по эффективному их использованию. Многомерная классификация проводилась в два этапа. Первый этап кластеризации включал иерархически-агломеративный метод, второй - итеративный метод «К-средних» [17].

Представленные выше методики являются достаточно подробными, однако не лишенными недостатков при применении их во Вьетнаме. ВИЭ Вьетнама находится на начальном этапе развития, поэтому информации об взаимосвязи уровня развития ВИЭ и социально-экономического показателя недостаточны для расчетов. В свою очередь, расчет только технических показателей не в полной мере может показать экономическое состояние региона. Поэтому предлагается новая модель формирования регионального кластера ВИЭ во Вьетнаме, которая представлена на рисунке 1. 


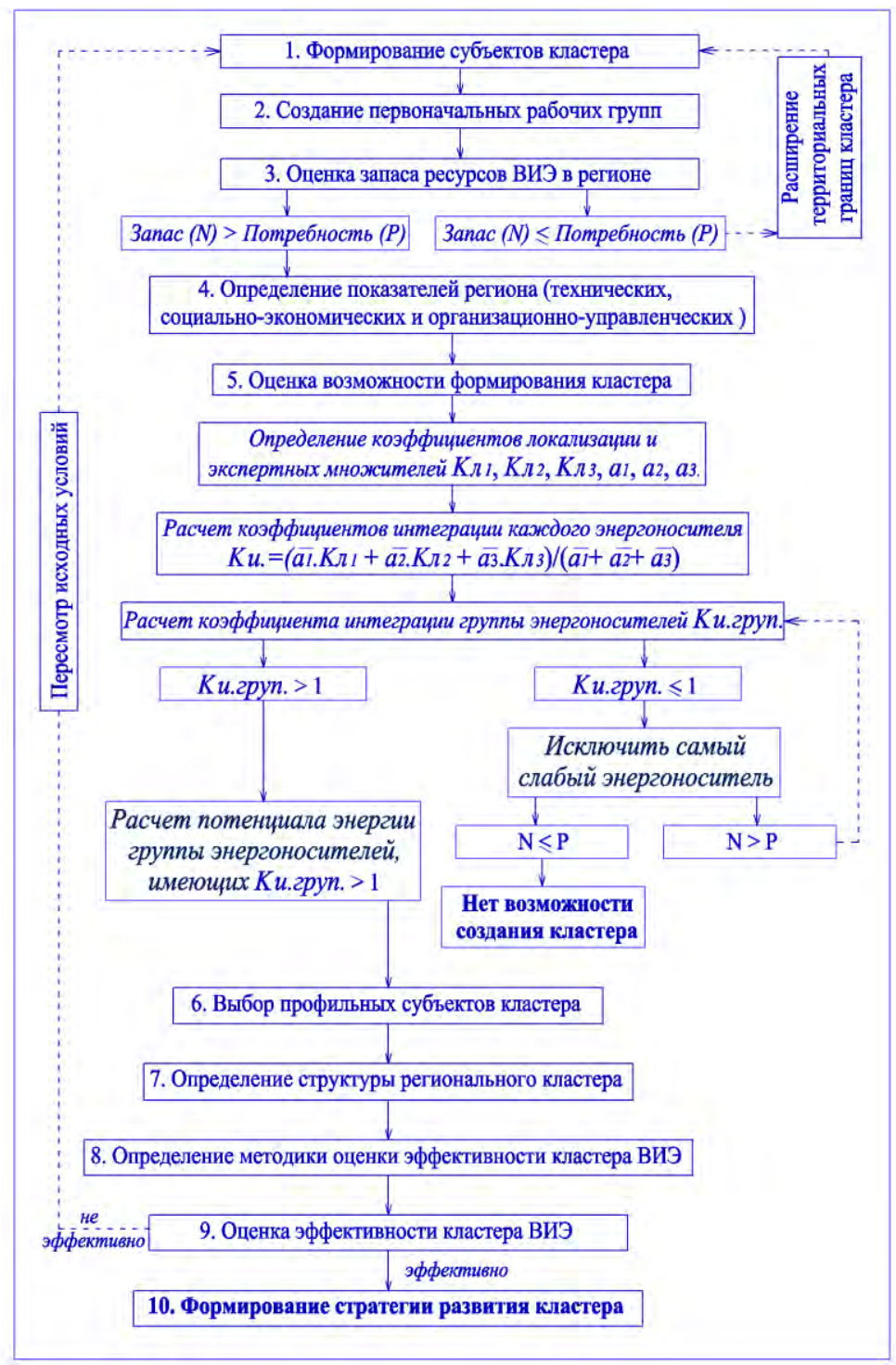

Рисунок 1 - Модель формирования регионального кластера ВИЭ во Вьетнаме

Модель формирования регионального кластера ВИЭ во Вьетнаме состоит следующих 10-ти шагов.

Первый шаг представляет собой формирование субъектов регионального кластера ВИЭ. Руководствуясь теорией регионального экономического кластера Портера, формулируются субъекты регионального кластера ВИЭ Вьетнама: высшие государственные органы власти и местного органы власти, учебные заведения, исследовательские институты, ключевые предприятия кластера, поставщики, потребителей и конкуренты. Далее определяется связь между субъектами кластера, основываясь на теории исследования региональных кластеров.

На втором шаге с целью установления связи между субъектами (правительство, предприятия, учебные заведения, другие экономические организации) необходимо создать первоначальные рабочие группы для формирования кластера. В первоначальные рабочие группы включаются информационная группа, группа исследования технологии, группа исследования рынка (покупка и продажа), группа управления финансовыми ресурсами, группа инженерно-технического проектирования, группа управления рабочими идеями.

На третьем шаге даётся предварительная оценка запаса ресурсов ВИЭ в регионе. При условии запаса ресурсов $(\mathrm{N})$ меньше, чем потребность $(\mathrm{P})$ - необходим поиск новых 
ресурсов. Возможно и расширение территориальных границ кластера или географическое определение кластера по другим критериям. В таком случае необходимо вернуться к шагу 1 , чтобы пересмотреть субъекты и размер кластера.

На четвертом шаге выбираются технические, социально-экономические и организационно-управленческие показатели развития региона. Техническими показателями являются технический потенциал, число часов использования установленной мощности энергоносителей (в год) и выработка электроэнергии. Социально-экономическими показателями являются выручка от реализации электроэнергии, число работников, объем инвестиции. К организационно-управленческим показателям относятся данные и информации о ресурсах; политика поддержки технологии и тарифов; программа развития; административное управление; инвестиции; финансирование; мониторинг; обучение персонала.

На пятом шаге оценивается возможность создания кластера. Оценка возможности создания кластера в области ВИЭ во Вьетнаме будет оцениваться с учетом возможности присоединении в кластер каждого отдельного энергоносителя ВИЭ и для расчета предлагается коэффициент интеграции группы энергоносителей ВИЭ $\left(K_{u . z p у n}\right)$ [3].

Коэффициент интеграции группы энергоносителей ВИЭ расчитывается по формуле:

$$
\mathrm{K}_{\text {и. груп }}=\frac{\sum_{i=1}^{r} N_{i} K_{\text {и.i }}}{\sum_{i=1}^{r} N_{i}} \text {, }
$$

$\mathrm{K}_{\text {и. груп }}-$ коэффициент интеграции группы энергоносителей ВИЭ;

$\mathrm{K}_{\text {и.i }}-$ коэффициент интеграции і-го энергоносителя ВИЭ в группе;

$r$ - количество энергоносителей ВИЭ в группе;

$N_{i}$ - запас ресурсов каждого энергоносителя ВИЭ.

$\mathrm{K}_{\text {и. } i}-$ коэффициент интеграции і-го энергоносителя ВИЭ рассчитывается на основе экспертного множителя $\left(\mathrm{a}_{j}\right)$ и трех коэффициентов локализации внутри отрасли по группам показателей $\left(K_{n j}, j=1,2,3\right)$ : техническим $\left(K_{л 1}\right)$, социально-экономическим $\left(K_{л 2}\right)$, организационно-управленческим $\left(K_{l 3}\right)$. Коэффициенты $K_{l 1}$ и $K_{л 2}$ определяются по параметрам и показателям отрасли, а коэффициент $K_{л 3}-$ по методу экспертной оценки.

Коэффициент интеграции і-го энергоносителя ВИЭ рассчитывается по формуле:

$$
\mathrm{K}_{\text {И. }}=\frac{\sum_{j=1}^{3} \bar{a}_{j} K_{\text {Л. } j}}{\sum_{j=1}^{3} \bar{a}_{j}}=\frac{\bar{a}_{1} K_{\text {Л.1 }}+\bar{a}_{2} K_{\text {Л. } 2}+\bar{a}_{3} K_{\text {Л. } 3}}{\bar{a}_{1}+\bar{a}_{2}+\bar{a}_{3}},
$$

где $K_{\text {..j }}$ - коэффициенты локализация і-го энергоносителя ВИЭ;

$\bar{a}_{j}-$ средневзвешенная величина экспертных множителей для і-го коэффициента локализации.

При $K_{\text {игрупn }}$ больше единицы, то рассматриваемая группа энергоносителей развита лучше, чем в среднем по стране, поэтому есть возможность кластеризации. И наоборот, если $K_{\text {игрупn }}<1$, то исключаются самые слабые энергоносители с наименьшим коэффициентом $K_{u}$ до тех пор, пока $K_{\text {иррупn }}>1$ и N > Р. При исключении самых слабых энергоносителей с наименьшим коэффициентом $K_{u}$, количество запасы ресурсов уменьшаться до потребность $(\mathrm{N} \leq \mathrm{P})$, то кластеризация региона невозможна.

На шестом шаге в соответствии с критериями отбора осуществляется выбор профильных субъектов кластера. Согласно структуре экономического кластера и опыту создания структуры энергетического кластера некоторых стран при выборе предприятий, участвующих в кластере, 
На седьмом шаге определяется структура регионального кластера ВИЭ, способная выражать отношение субъектов внутри и вне кластера, а также на данном шаге формируются организационная структура кластера и стратегии развития регионального кластера, которой является основой для разработки политики в области ВИЭ.

На восьмом шаге определяется методика оценки эффективности регионального кластера. Методика оценки эффективности будет определять показатели нормы, используемые при анализе и оценке осуществимости проекта регионального кластера ВИЭ.

На девятом шаге после определения методики оценки эффективности выполняется оценка эффективности и возможность осуществление на практике регионального кластера ВИЭ. В случае, если оценка эффективности положительная, возможен переход к десятому шагу. В противном случае - необходимо вернуться к первому шагу.

На десятом шаге реализуется проект регионального кластера ВИЭ. В соответствии с этим необходимо сформулировать стратегии развития кластера и спланировать совместные действия рабочих групп для предложения методов и стратегии развития регионального кластера ВИЭ. Стратегия развития регионального кластера ВИЭ разрабатывается на краткосрочную (1 год) и долгосрочную (3 - 5 лет) перспективу.

На основе предложенной модели проведем сравнительный анализ моделей формирования региональных кластеров. Сравнительный анализ моделей формирования региональных кластеров представлена в таблице 1.

Таблица 1 - Сравнительный анализ моделей формирования региональных кластеров

\begin{tabular}{|l|c|c|c|c|c|c|}
\hline & Портер М. & $\begin{array}{c}\text { Денисов } \\
\text { Г. А. }\end{array}$ & $\begin{array}{c}\text { Батталова } \\
\text { А. А }\end{array}$ & $\begin{array}{c}\text { Киушкина } \\
\text { В. Р. }\end{array}$ & $\begin{array}{c}\text { Велькин } \\
\text { В. И. }\end{array}$ & $\begin{array}{c}\text { Методика } \\
\text { автора }\end{array}$ \\
\hline $\begin{array}{l}\text { Формирование } \\
\text { субъектов } \\
\text { кластера }\end{array}$ & + & - & + & - & - & + \\
\hline $\begin{array}{l}\text { Создание } \\
\text { первоначальных } \\
\text { рабочих групп }\end{array}$ & - & + & + & - & - & \\
\hline $\begin{array}{l}\text { Оценка запаса ре- } \\
\text { сурсов }\end{array}$ & - & - & + & + & + & + \\
\hline $\begin{array}{l}\text { Выбор техниче- } \\
\text { ские, соц-эк-кие, } \\
\text { орг.-управ-кие по- } \\
\text { казателей }\end{array}$ & - & - & - & - & - & + \\
\hline $\begin{array}{l}\text { Оценка } \\
\text { эффективности ре- } \\
\text { гионального кла- } \\
\text { стера }\end{array}$ & + & + & + & + & + & + \\
\hline
\end{tabular}

На основе сравнительного анализа моделей формирования региональных кластеров, можем сделать вывод, что только в предложенной модели рассматриваются намного больше показателей, которые отражаются технические, социально-экономические и организационно-управленческие данные о ВИЭ. Что является самым оптимальным подходом для оценки возможности формирования кластера ВИЭ во Вьетнаме.

Для апробации методики был использован регион Нинь Туан - Бинь Туан. Регион Нинь Туан - Бинь Туан (Ninh Thuan - Binh Thuan) расположен в Юго-Восточной области. В Нинь Туан - Бинь Туан имеется большое количество экологических зон, а также многообразна и природно-климатическая среда этих зон. Наличие моря, плоскогорья и горных районов создает благоприятные условия для развития ВИЭ. Нинь-Туан - Бинь Туан регион с устойчивыми ветрами в течение всего года, технический потенциал ветровой 
энергии региона оценивается в почти 4000 МВт. В регионе высокая интенсивность солнечного излучения среднее количество солнечных часов за год составляет от $2200-$ 2800 ч. Годовая потенциальная мощность солнечной энергии достигает до 14000 МВт. Малая ГЭС в этой области имеет очень низкий технический потенциал, который составляет всего лишь 40,7 МВт [19].

Исходные данные необходимые для расчета $K_{l 1}$ и $K_{л 2}$ представлены в таблице 2.

Таблица 2 - Исходные данные необходимые для расчета $\mathrm{K}_{л 1}$ и $\mathrm{K}_{л 2}$

\begin{tabular}{|c|c|c|c|c|c|c|c|}
\hline \multirow[t]{2}{*}{ Показатели } & \multirow{2}{*}{ Ед. изм } & \multicolumn{2}{|c|}{ Солнце } & \multicolumn{2}{|c|}{ Ветер } & \multicolumn{2}{|c|}{ МГЭС } \\
\hline & & регион & страна & регион & страны & регион & страна \\
\hline $\begin{array}{l}\text { Технический } \\
\text { потенциал } \\
\text { (мощность) }\end{array}$ & MBT & 13963 & 413680 & 3929 & 9000 & 40,7 & 1000 \\
\hline \begin{tabular}{|l|} 
Число часов \\
использования уста- \\
новленной мощности \\
энергоносителей
\end{tabular} & $\frac{\text { час }}{\text { год }}$ & 2400 & 2000 & 2200 & 2000 & 4000 & 4000 \\
\hline \begin{tabular}{|l|} 
Выработка \\
электроэнергии
\end{tabular} & ГВт.ч & 33511 & 827360 & 8644 & 18000 & 162,8 & 4,000 \\
\hline $\begin{array}{l}\text { Собственные } \\
\text { нужды }\end{array}$ & $\%$ & $1,5 \%$ & $1,5 \%$ & $1,5 \%$ & $1,5 \%$ & $1 \%$ & $1 \%$ \\
\hline $\begin{array}{l}\text { Тариф } \\
\text { на электроэнергию }\end{array}$ & цент/кВт·ч & \multicolumn{2}{|c|}{10,80} & \multicolumn{2}{|c|}{9,80} & \multicolumn{2}{|c|}{4,55} \\
\hline Выручка & $\begin{array}{c}\text { млн } \\
\text { долл.США }\end{array}$ & 3565 & 88015 & 834 & 1738 & 7,25 & 178 \\
\hline \begin{tabular}{|l} 
Удельная стоимость \\
установленной \\
мощности \\
\end{tabular} & $\begin{array}{c}1000 \\
\text { долл.США/ } \\
\text { МВт }\end{array}$ & \multicolumn{2}{|c|}{1800} & \multicolumn{2}{|c|}{1750} & \multicolumn{2}{|c|}{1500} \\
\hline Объем инвестиций & $\begin{array}{c}\text { млН } \\
\text { долл.США }\end{array}$ & 25133 & 744624 & 6876 & 15750 & 61 & 1500 \\
\hline
\end{tabular}

Рассчитаем коэффициент интеграции і-го энергоносителя $\left(K_{u}\right)$ и коэффициент группы энергоносителей $\left(K_{\text {ирупn }}\right)$ ВИЭ для региона Нинь Туан - Бинь Туанна основе исходных данных. Расчет коэффициентов интеграция для энергоносителя и группы энергоносителей представлен в таблице 3.

Таблица 3 - Расчет коэффициентов интеграции энергоносителя $\left(\mathrm{K}_{\text {и) }}\right.$ и группы

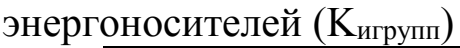

\begin{tabular}{|c|c|c|c|c|c|c|c|c|c|}
\hline \multirow{4}{*}{ ret } & \multicolumn{9}{|c|}{ ВИЭ } \\
\hline & \multicolumn{3}{|c|}{ Ветер } & \multicolumn{3}{|c|}{ Солнце } & \multicolumn{3}{|c|}{ МГЭС } \\
\hline & \multicolumn{3}{|c|}{$Э=8,644$ млрд. кВТ·ч } & \multicolumn{3}{|c|}{$Э=33,511$ млрд. кВт·ч } & \multicolumn{3}{|c|}{$Э=0,163$ млрд. кВт·ч } \\
\hline & Клј & $\overline{a_{j}}$ & $\overline{a_{j}}$ Клj & Клј & $\overline{a_{J}}$ & $\overline{a_{j}}$ Клj & Клј & $\overline{a_{j}}$ & $\overline{a_{j}}$ Клj \\
\hline 1 & 6,99 & 3,0 & 20,98 & 0,91 & 3,0 & 2,73 & 0,90 & 3,0 & 2,71 \\
\hline 2 & 10,09 & 2,0 & 20,17 & 0,81 & 2,0 & 1,63 & 0,90 & 2,0 & 1,80 \\
\hline 3 & 1,00 & 1,8 & 1,80 & 2,00 & 2,0 & 4,00 & 2,00 & 2,0 & 4,00 \\
\hline
\end{tabular}


Окончание таблицы 3

\begin{tabular}{|c|c|c|c|c|c|}
\hline Ки & 6,316 & 1,194 & & 1,215 & \\
\hline \multirow{4}{*}{ 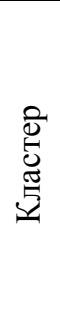 } & $\mathrm{K}_{\text {игрупп }}($ Ветер и Солнце $)=$ & 2,244 & $\ni=$ & 42,155 & $\begin{array}{l}\text { млрд. } \\
\kappa \mathrm{B} \cdot ч \\
\end{array}$ \\
\hline & $\mathrm{K}_{\text {игрупп }}($ Ветер и МГЭС) $=$ & 6,221 & $Э=$ & 8,807 & $\begin{array}{l}\text { млрд. } \\
\text { кВт·ч }\end{array}$ \\
\hline & $\mathrm{K}_{\text {игрупп }}($ Солнце и МГЭС $)=$ & 1,194 & $\ni=$ & 33,674 & $\begin{array}{l}\text { млрд. } \\
\text { кВт·ч }\end{array}$ \\
\hline & $\mathrm{K}_{\text {игрупп }}($ Ветер, Солн. и МГЭС $)=$ & 2,240 & $\ni=$ & 42,318 & $\begin{array}{l}\text { млрд. } \\
\kappa \mathrm{B} \cdot ч \\
\end{array}$ \\
\hline
\end{tabular}

По результатам расчета можно сделать вывод: так как во всех случаях $\mathrm{K}_{\text {игрупп }}>1$, то рассматриваемые выше группы энергоносителей в регионе Нинь Туан - Бинь Туан будут иметь возможность для создания кластера.

Таким образом, предложенная модель формирования кластера ВИЭ позволяет более точно оценить возможность кластеризации ВИЭ в условиях развития Вьетнама. Для Вьетнама формирование энергетического кластера может стать эффективным решением энергетических проблем страны. Кластеры ВИЭ повышают экономическую ценность, создавая рабочие группы в отраслях ВИЭ и улучшая эффективность отрасли посредством оказания поддержки.

\section{СПИСОК ИСПОЛЬЗОВАННЫХ ИСТОЧНИКОВ}

1. Портер, М. Международная конкуренция / М. Портер. / Под ред. В. Д. Щетинина. М.: Международные отношения, 1993, - 199 с.

2. Нго Ань Тует. Формирование модели энергетического кластера возобновляемых источников энергии во Вьетнаме / Нго Ань Тует // Экономическая наука сегодня, Выпуск № 5. - Минск, 2017. - С. 421-434.

3. Нго Ань Тует. Предлагаемый подход к развитию возобновляемых источников энергии во Вьетнаме / Нго Ань Тует // Вестник БарГУ. Серия: Исторические науки и археология. Экономические науки. Юридические науки. В. 4., 2016 г. / БарГУ; редкол.: В. И. Кочурко (главный редактор журнала) [и др.]. - Баранович: БарГУ, 2016. - С. 79-83.

4. Дондокова, Б. С. Кластеры или ТПК: сходства и различия / Б. С. Дондокова // Горный информационно-аналитический бюллетень (научно-технический журнал), № 1. - изд. Горная книга. - Москва, 2015. - С. 381-385.

5. Анисова, Н. А. Развитие теории кластеров: типовая модель и примеры применения: Монография / Н. А. Анисова. - М: Библио-глобус, 2014. - 84 с.

6. Котляров, Н.Н. Зарубежный опыт формирования кластерных систем / Н. Н. Котляров, Л. В. Левченко // Мировая экономика и международные экономические отношения, Экономические науки, 10(119), 2014. - С. 105-110.

7. Маркушина, Е. В. Кластеры и кластерные стратегии в развитии экономики региона / Е. В. Маркушина // Проблемы современной экономики, № 2 (34). - 2010. - С. 321-323.

8. Свистунова, И. Н. Кластерный подход как основа устойчивого развития региона / И. Н. Свистунова // Интернет-журнал «НАУКОВЕДЕНИЕ». - Том 7. - № 5. - Сентябрь - октябрь, 2015. - Режим доступа: http://publ.naukovedenie.ru - Дата доступа: 05.01.2018.

9. Чень Цзаньчжан. Обзор развития теории промышленных кластеров / Чень Цзаньчажан, В. М. Пизенгольц. 
10. Глоова, А. В. Кластер как инструмент повышения конкурентоспособности региона / А. В. Глоова, О. С. Зыбин // Вестник ЮУрГУ, № 20, серия «Экономика и менеджмент», выпуск 14. - 2010. - С. 101-105.

11. Волков, В. И. Кластер как инструмент повышения конкурентоспособности и инновационной активности регионов / В. И. Волков, Е. А. Малицкая // Самоуправление, №10. - октябрь 2012. - С. 10 - 14.

12. Садриев, А. Р. Инновационные кластеры в электроэнергетике: проблемы формирования и перспективы развития / А. Р. Садриев / Экономика и управление, 2 (64). - СанктПетербург: СПБУТУиЭ, 2011. - С. 25-29.

13. Батталова, А. А., Механизм развития топливно-энергетического комплекса на основе создания кластера: автореф. дисс. к.э.н.: 08.00.05 / А. А. Батталова. - Уфа, 2013. $-22 \mathrm{c}$.

14. Игумнов, П. В. Основные принципы анализа энергетического комплекса с применением теории кластеров и автоматического метода карт кластеризации / П. В. Игумнов // Власть и управление на востоке России. - Хабаровск, 2012. - С. 69 - 75.

15. Лаврикова, Ю. Г. Зеленая экономика в кластерном развитии / Ю. Г. Лаврикова, Малыш Е. В // Вестник УРФУ, серия: Экономика и управление. - Екатеринбург, 2014. C. $120-133$.

16. Велькин, В. И. Разработка математической модели и программы для расчета кластера ВИЭ / В. И. Велькин, М.И.Логинов, Е.В.Чернобай // Научно-практическая конференция «Энерго- и ресурсоэффективность малоэтажных жилых зданий», Институт теплофизики им. С. С. Кутателадзе СО РАН, 19-20 марта 2013 г.

17. Киушкина, В. Р. Кластерный анализ потенциала возобновляемых источников энергии в Республике Саха (Якутия) // В. Р. Киушкина, Я. О. Ощепкова // Интернет-журнал «НАУКОВЕДЕНИЕ» Выпуск 4 (23). Июль - август 2014. Опубликовать статью в журнале http://naukovedenie.ru.

18. Денисов, Г. А., Формирование системы кластерного управления региональной экономикой (на материалах республики Адыгея): автореф. дисс. к.э.н.: 08.00.05 / Г. А. Денисов. - Майкоп, 2011. - 28 с.

19. План развития национальной электроэнергетики Вьетнама на 2011 - 2020 гг. с учетом прогноза до 2030 г.», утвержденного постановлением Правительства Социалистической Республики Вьетнам от 18 марта 2016 г., № 428/QD-TTg.

\section{REFERENCES}

1. Porter, M. Mezhdunarodnaya konkurenciya / M. Porter. / Pod red. V. D. SHCHetinina. - M.: Mezhdunarodnye otnosheniya, 1993, - 199 s.

2. Ngo An' Tuet. Formirovanie modeli ehnergeticheskogo klastera vozobnovlya-emyh istochnikov ehnergii vo V'etname / Ngo An' Tuet // EHkonomicheskaya nauka segodnya, Vypusk № 5. - Minsk, 2017. - S. 421-434.

3. Ngo An' Tuet. Predlagaemyj podhod k razvitiyu vozobnovlyaemyh istochnikov ehnergii vo V'etname / Ngo An' Tuet // Vestnik BarGU. Seriya: Istoricheskie nauki i arheologiya. EHkonomicheskie nauki. YUridicheskie nauki. V. 4., 2016 g. / BarGU; red-kol.: V. I. Kochurko (glavnyj redaktor zhurnala) [i dr.]. - Baranovich: BarGU, 2016. - S. 79-83.

4. Dondokova, B. S. Klastery ili TPK: skhodstva i razlichiya / B. S. Dondokova // Gornyj informacionno-analiticheskij byulleten' (nauchno-tekhnicheskij zhurnal), № 1. - izd. Gornaya kniga. - Moskva, 2015. - S. 381-385.

5. Anisova, N. A. Razvitie teorii klasterov: tipovaya model' i primery pri-meneniya: Monografiya / N. A. Anisova. - M: Biblio-globus, 2014. - 84 s. 
6. Kotlyarov, N. N. Zarubezhnyj opyt formirovaniya klasternyh sistem / N. N. Kotlyarov, L. V. Levchenko // Mirovaya ehkonomika i mezhdunarodnye ehkonomiche-skie otnosheniya, EHkonomicheskie nauki, 10 (119), 2014. - S. 105-110.

7. Markushina, E. V. Klastery i klasternye strategii v razvitii ehkonomiki regiona / E. V. Markushina // Problemy sovremennoj ehkonomiki, № 2 (34). - 2010. - S. 321-323.

8. Svistunova, I. N. Klasternyj podhod kak osnova ustojchivogo razvitiya re-giona / I. N. Svistunova // Internet-zhurnal «NAUKOVEDENIE». - Tom 7. - № 5. - Sentyabr' - oktyabr', 2015. - Rezhim dostupa: http://publ.naukovedenie.ru - Data dostupa: 05.01.2018.

9. CHen' Czan'chzhan. Obzor razvitiya teorii promyshlennyh klasterov / CHen' Czan'chazhan, V. M. Pizengol'c

10. Gloova, A. V. Klaster kak instrument povysheniya konkurentosposobnosti regiona / A. V. Gloova, O. S. Zybin // Vestnik YUUrGU, № 20, seriya «EHkonomika i me-nedzhment», vypusk 14. - 2010. - S. 101-105.

11. Volkov, V. I. Klaster kak instrument povysheniya konkurentosposobnosti i innovacionnoj aktivnosti regionov / V. I. Volkov, E. A. Malickaya // Samouprav-lenie, №10. - oktyabr' 2012. - S. $10-14$.

12. Sadriev, A. R. Innovacionnye klastery v ehlektroehnergetike: problemy formirovaniya i perspektivy razvitiya / A. R. Sadriev / EHkonomika i upravlenie, 2 (64). - SanktPeterburg: SPBUTUiEH, 2011. - S. 25-29.

13. Battalova, A. A., Mekhanizm razvitiya toplivno-ehnergeticheskogo kompleksa na osnove sozdaniya klastera: avtoref. diss. k.eh.n.: 08.00.05 / A. A. Battalova. - Ufa, 2013. - 22 s.

14. Igumnov, P. V. Osnovnye principy analiza ehnergeticheskogo kompleksa s primeneniem teorii klasterov i avtomaticheskogo metoda kart klasterizacii / P. V. Igumnov // Vlast' i upravlenie na vostoke Rossii. - Habarovsk, 2012. - S. 69 - 75.

15. Lavrikova, Yu. G. Zelenaya ehkonomika v klasternom razvitii / Yu. G. Lavriko-va, Malysh E. V // Vestnik URFU, seriya: EHkonomika i upravlenie. - Ekaterinburg, 2014. S. $120-133$.

16. Vel'kin, V. I. Razrabotka matematicheskoj modeli i programmy dlya rascheta klastera VIEH / V. I. Vel'kin, M. I. Loginov, E. V. CHernobaj // Nauchno-prakticheskaya konferenciya «EHnergo- i resursoehffektivnost' maloehtazhnyh zhilyh zdanij», Insti-tut teplofiziki im. S. S. Kutateladze SO RAN, 19-20 marta 2013 g.

17. Kiushkina, V. R. Klasternyj analiz potenciala vozobnovlyaemyh istochnikov ehnergii v Respublike Saha (YAkutiya) // V. R. Kiushkina, Ya. O. Oshchepkova // Internetzhurnal «NAUKOVEDENIE» Vypusk 4 (23). Iyul' - avgust 2014. Opublikovat' stat'yu v zhurnale - http://naukovedenie.ru.

18. Denisov, G. A., Formirovanie sistemy klasternogo upravleniya regional'-noj ehkonomikoj (na materialah respubliki Adygeya): avtoref. diss. k.eh.n.: 08.00.05 / G. A. Denisov. - Majkop, 2011. - $28 \mathrm{~s}$.

19. Plan razvitiya nacional'noj ehlektroehnergetiki V'etnama na 2011 - 2020 gg. S uchetom prognoza do 2030 g.», utverzhdennogo postanovleniem Pravitel'stva Socia-listicheskoj Respubliki V'etnam ot 18 marta 2016 g., № 428/QD-TTg.

Статья поступила в редакичю 15 января 2018 года. 